\title{
A New Series
}

\section{BLACK LTIERATURE AND CULTURE \\ Houston A. Baker, Jr., Series Editor}

This major new series will publish scholarly works devoted to the literatures and cultures of the African diaspora. Its goal is the dissemination of new and revised assessments of key issues in African, Caribbean, and Afro-American intellectual history. The Black Literature and Culture series will serve as a catalyst for growth and a source of coherence for this dynamic field.

\section{Announcing the first volume:}

\section{AFRO-AMERICAN}

\section{LITERARY STUDY IN THE 1990s}

Edited by Houston A. Baker, Jr. and Patricia Redmond

Featuring the work of the most distinguished scholars in the field, this volume assesses the state of Afro-American literary study and projects a vision of that study for the coming decade. Beginning with an essay on canon formation, the volume proceeds to treat such issues as genre, gender, theory, and performance.

Contributors: William L. Andrews, Michael Awkward, Houston A. Baker, Jr., Kimberly W. Benston, Genevieve Fabre, Henry Louis Gates, Jr., Donald B. Gibson, Mae G. Henderson, Stephen E. Henderson, Barbara E. Johnson, Deborah E. McDowell, Nellie Y. McKay, Robert G. O'Meally, Sandra Pouchet Pacquet, Arnold Rampersad, Hortense J. Spillers, Robert B. Stepto, Eleanor W. Traylor, Cheryl A. Wall, and Richard Yarborough.

Cloth $\$ 24.95252$ pages

\section{THE UNIVERSITY OF CHICAGO PRESS}

5801 South Ellis Avenue Chicago, IL 60637 


\section{People of the Dawn}

\section{Volume 2 in the Holme Trilogy}

By Jan Fridegård

Translated, with a foreword and notes, by Robert E. Bjork

"One of the most beautiful pieces of literature I know. Even though it is set in Viking times, it touches on many issues relevant today." - Torborg Lundell. "A vast amount of historically accurate and largely unromanticized information about life during the $\mathrm{Vi}$ king era." - Rochelie Wright. The Vikings, romanticized in so many books and movies, are not heroes to their slaves, who find the strength to sland up to them in People of the Dawn. The clash between paganism and Christianity splits 9th-century Sweden in this second volume of Jan Fridegård's much-admired Holme Trilogy. Its cinematic clarity and vividness is perfectly realized in

\section{The Blue Mother}

\section{By Christer Kihlman}

Translated by Joan Tate

Afterword by George Schoolfield

"A tour-de-force, both in conception and in technique, a streamof-consciousness novel of considerable psychological depth. It has power and intelligence and mood reminiscent of a Bergman movie." - Robert E. Bjork. What lies beneath the superficial respectability of an upper-class Finland-Swedish family is revealed with horrifying intensity in The Blue Mother. The novel is narrated by two brothers - Benno, shy and sensitive and Ionely, most alive in his sexual fantasies and tortured by temptation, and Rat, a writer who fritters away his talent in

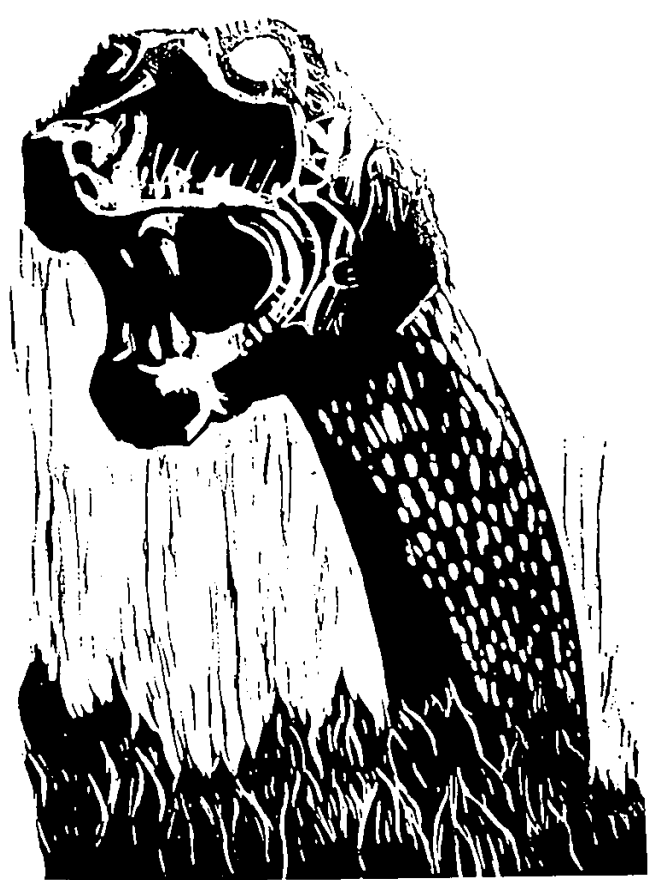

Robert E. Bjork's prize-winning English translation.

A volume in our series,

Modern Scandinavian Literature in Translation

$\$ 19.95$ cloth, $\$ 8.50$ paper

also available

Land of Wooden Gods

Volume 1 in the Holme Trilogy

$\$ 19.95$ cloth, $\$ 8.95$ paper rebellion and distrusts emotion. They measure themselves against the memory of a cherished and superior older brother, Robby, who was killed in the war in 1943. Both brothers pass from self-destruction and darkest despair to the promise of happiness, security, and harmony.

A volume in our series,

Modern Scandinavian Literature in Translation $\$ 27.95$ cloth, $\$ 11.95$ paper

Please write for a complete listing of our Modern Scandinavian Literature in Translation series NebraSka 